\title{
Conceptive Estrus Behavior in Three Bottlenose Dolphins (Tursiops truncatus)
}

\author{
Holley Muraco ${ }^{1 *}$ and Stan A. Kuczaj II $^{2}$ \\ ${ }^{1}$ Mississippi State University \\ ${ }^{2}$ University of Southern Mississippi \\ *Corresponding author (Email: holley@ muraco.biz)
}

Citation - Muraco, H., \& Kuczaj, S. A. II. (2015). Conceptive estrus behavior in three bottlenose dolphins (Tursiops truncatus). Animal Behavior and Cognition, 2(1), 30-48. doi: 10.12966/abc.02.03.2015

\begin{abstract}
Bottlenose dolphins (Tursiops truncatus) are a highly promiscuous species that routinely engage in socio-sexual interactions, yet relatively little has been reported about actual estrus behavior. For this study of three female dolphins located at two aquarium facilities, 20 reproductive behaviors were investigated during three conceptive estrous cycles with known endocrinology. Reproductive behaviors increased with estradiol levels and peak occurrences of behaviors were observed during the luteinizing hormone (LH) surge. Two novel behaviors were observed: (1) genital tracking, an investigatory-type behavior, and (2) immobility, a novel form of standing heat estrus. These behaviors appeared to communicate reproductive readiness and increased copulation success. A total of 314 occurrences of estrus behavior were recorded in 10 hours of footage from the three focal females, and copulation spanned from day -9 to day 0 in one dominant female. Sexual interactions during estrus included femaleto-female, immature male-to-female, mature male-to-immature male and masturbation with toys. During estrus, focal females received more behavioral attention than they initiated, and passive and active dorsal fin mounting between females was the most frequent behavior. These dolphins showed behavioral patterns similar to those reported in estrus cows where genitals are nuzzled, females mount and are mounted by other females, and standing heat intensity increases as LH levels rise.
\end{abstract}

Keywords - Dolphin, Behavior, Estrus, Reproduction, Conception, Copulation, Estrous

Little is known about conceptive dolphin estrus behavior despite the fact that dolphins routinely engage in overtly sexual interactions (Ridgway, 1972). Most observations of sexual behavior involve socio-sexual behaviors rather than true conceptive mating behaviors (Connor et al., 1992; Dudzinski, 1998; Puente \& Dewsbury, 1976; Wells, 1984). Dolphin non-conceptive socio-sexual behaviors may involve immature individuals, same sex individuals, and copulation during the non-conceptive period (Furuichi, Connor, \& Hashimoto, 2014). In addition, male and female dolphins masturbate with objects and the appendages of other dolphins (Ridgway, 1972). Reflexive penile erection occurs in male dolphin calves within 48 hours of birth, and male calves are able to assume the copulatory position within weeks (Ridgway, 1972). A dependent male calf will often copulate with his mother (Ridgway, 1972). Dolphins are not the only animals to participate in non-conceptive sexual behaviors. Many social mammals engage in these sorts of socio-sexual behaviors, including mounting by or on pre-pubertal animals, mounting between same sex animals, mounting without thrusting, and intromission and ejaculation (Hanby \& Brown, 1974).

There are few studies that document conceptive dolphin sexual behavior. Connor et al. (1992) noted that male bottlenose dolphins (Tursiops sp.) in Shark Bay Australia form alliances to cooperatively herd and control females. Reproductive states of the herded females could not be determined, but the 
authors hypothesized that the females were in estrus. Dudzinski (1998) studied Atlantic spotted dolphins (Stenella frontalis) in the Bahamas, and noted that much of the affliative social behavior included genital oriented behaviors, rubbing and body to body contact. Most of the socio-sexual behaviors in this study occurred between animals of the same age range and of the same sex, but reproductive states of the animals could not be specified.

In a study of captive spinner dolphins (Stenella longirostris), tactile, contact and socio-sexual behaviors were observed along with one estradiol sample (Wells, 1984). The sexual behaviors observed appeared to serve social functions rather than reproductive ones (Wells, 1984). Puente and Dewsbury (1976) conducted observations on captive bottlenose dolphins and documented nine potential courtship patterns that involved mouthing, nuzzling, rubbing, stroking, leaping, chasing, head butting, display and yelping as well as copulation. However the reproductive status of the female dolphins was unknown. Female dolphins being monitored for artificial insemination showed estrus behaviors of "listing on the water surface, sinking and reduced responsiveness during training sessions" 12-48 hrs prior to ovulation (Robeck et al., 2005, p. 668).

In mammals, the period of female sexual receptivity, called estrus, heat, or lordosis occurs when the female will accept the male for copulation (Bearden, Fuquay, \& Willard, 2004; Hunter, 1980; Pineda \& Dooley, 2003), and estrus behaviors imply the act of mounting, intromission and pelvic thrusts (Austin \& Short, 1972). Additionally, estrus behaviors in many mammals may include immobility, raising the hindquarters, arching the back, restlessness, irritability and excitability (Bearden et al., 2004; Hunter, 1980). Cows in estrus will solicit mounts and mount other cows, smell the vulva of other cows, raise and switch their tail and spend more time walking and less time resting and feeding (Bearden et al., 2004). Estrus pigs will assume a rigid stance, called the lordosis reflex, when pressure is applied to their back (Austin \& Short, 1972).

To truly understand if the sexual behaviors of dolphins are for conceptive purposes, serial endocrinology and known reproductive states are critical, and to date no detailed sexual behavioral study has been conducted on dolphins with a known reproductive state. The work presented in this paper is the first to analyze the sexual behavior of bottlenose dolphins at two different aquaria during three conceptive estrous cycles, two (one nulliparous and one parous) from natural breeding and one (nulliparous) from artificial insemination.

\section{Method}

\section{Experimental Ethics}

All animals, materials and methods used in the study were individually evaluated by the facility's Internal Animal Care and Use Committee (IACUC) to ensure safety, health and well-being of the animals. Samples were taken during routine behaviors in which the animals were conditioned to participate.

\section{Animals}

Animals 1-5 (Table 1) were housed at facility A, a 3,141,892-L manufactured seawater pool, maintained at $21-23^{\circ} \mathrm{C}$ year-round. Animal diets consisted of frozen thawed herring ( $C$. harengus), capelin (M. villosus), sardine (Sardina pilchardus), and squid (L. opalescens) for daily totals of $5-10 \mathrm{~kg}$ per animal. Animals 6 and 7 (Table 1) were located at facility B and housed in a 2717.93 L manufactured seawater pool maintained at $21-22^{\circ} \mathrm{C}$ year round and fed a diet of whole frozen thawed herring (Clupea harengus) and capelin (Mallotus villosus) ranging from $8-15 \mathrm{~kg}$ daily. 
Table 1

\begin{tabular}{llllll}
\multicolumn{2}{l}{ Animals in Study } & & & \\
\hline Animal & Facility* & Sex & Birthdate & Weight (kg) & Repro History \\
\hline 1 & A & F & $11 / 1975$ & 191.86 & Parous \\
2 & A & F & $5 / 1997$ & 176.44 & Nulliparous \\
3 & A & F & $3 / 2000$ & 159.66 & Immature \\
4 & A & M & $2 / 2003$ & 165.15 & Immature \\
5 & A & M & $8 / 1989$ & 201.35 & Proven Sire \\
6 & B & F & $9 / 2004$ & 134.00 & Nulliparous \\
7 & B & F & $8 / 2003$ & 163.00 & Nulliparous \\
8 & B & M & $11 / 1969$ & 210.00 & Proven Sire \\
9 & B & F & $7 / 1998$ & 220.00 & Parous \\
10 & B & F & $10 / 2005$ & 130.00 & Nulliparous \\
\hline
\end{tabular}

\section{Statistics}

Arithmetic means and standard deviations are presented as $\mathrm{M}+/-\mathrm{SD}$. Calculations were done using SYSTAT software (Systat Software, Inc. 225 W Washington St., Suite 425, Chicago, IL 60606). Inter-rater reliability for coding behaviors was calculated using one hour of continuous footage that was independently rated by each coder.

\section{Behavioral Conditioning}

Operant conditioning techniques were used to train the dolphins for urine and vaginal swab sampling. Behaviors were positively reinforced and slow approximations were taken until the dolphin was fully conditioned for daily sampling and exams.

\section{Urine Collection}

The dolphin was trained to urinate on cue by applying hand pressure to the bladder resulting in reflexive urination. The reflexive behavior was paired with primary reinforcement to increase the frequency, and over time the dolphin was conditioned to urinate by the application of gentle pressure to the bladder. For collection, the dolphin would beach laterally on a shallow ledge so that the genital slit was wiped clean and dry with gauze. A 50-ml sterile plastic specimen cup was placed under the urethra and gentle pressure was applied to the bladder. The urine was caught in the cup as it freely flowed from the urethra. An average of $5-10 \mathrm{ml}$ of urine was collected from all study animals. Urine was frozen at $17{ }^{\circ} \mathrm{C}$ in 5-ml increments immediately following collection. Urine for the study was collected in the AM (8 AM - 11 AM) for the study unless noted.

\section{Ultrasonography}

Real-Time B-Mode trans-abdominal ultrasound imaging was utilized. For all animals, ultrasound exams were conducted as needed and exams typically lasted $3-5$ min. For ovary and fetus visualization, 
the dolphins were trained to float laterally and stationary at the water's surface. The blowhole was submerged, but the animal could lift her head and take a breath as needed. For animal 1, a Sonosite 180 Plus ultrasound machine with a $5-2 \mathrm{MHz}$ transducer (Sonosite Inc., 21919 30th Drive SE, Bothell, WA 98021-3904, USA) was used and images recorded using either the internal digital memory of the machine or by the use of an Archos 605 Audio/Visual Player (Archos Inc., 7951 E. Maplewood Avenue \#260 Greenwood Village, CO 80111 USA). For animals 6 and 7, a Sonosite Titan portable ultrasound machine with a 5-2 MHz curvilinear transducer (Sonosite Inc. 21919 30th Drive SE, Bothell, WA 98021-3904, USA) was used. Images were digitally captured using the internal digital memory of the machine or by the use of an Archos 605 Audio/Visual Player (Archos Inc. 7951 E. Maplewood Avenue \#260 Greenwood Village, CO 80111 USA).

\section{Hormone Testing Progesterone, Estradiol and Lutenizing Hormone}

Urinary progesterone (uP) and estradiol-17 beta (uE2) was measured using an electrochemiluminescent immunoassay (ECLIA) tested with the Elecsys 2010 instrument (Roche Diagnostics, Mannheim, Germany) at Clinical Pathology Laboratory in Las Vegas (4275 S. Burnham Ave, Suite 325, Las Vegas, NV 89119, USA) as previously reported (Muraco et al., 2009). Fresh collected chilled or frozen urine was transferred to the laboratory via courier. Urinary luteinizing hormone $(\mathrm{uLH})$ was measured using the ICG Canine Witness ${ }^{\circledR}$ Luteinizing Hormone Assay (Witness Synbiotics Corp., Kansas City, MO, USA). The assay provides a rapid, semi-quantitative visible color band in the presence of dolphin LH (Muraco et al., 2009). Dolphin urine was applied to the test strip either directly following collection, or, if frozen, after thawing. A $100-\mu 1$ volume of neat urine was placed onto the test strip and results were obtained in less than $1 \mathrm{hr}$ after application. The LH surge was identified when the test band became darker than the control band.

\section{Social Grouping}

Animal 5, a mature proven sire, arrived to facility A on 4/9/06 and remained fully separated from animals $1-4$ for quarantine purposes. On 4/26/06, the quarantine ended and dolphins $1-5$ were able to see and hear one another for the first time. However, they remained separated by a nine meter canal and two closed see-through metal gates. On 5/16/06, animal 4 was introduced to animal 5, and animals $1-3$ can see and hear animals 4 and 5 through closed see-through metal gates. Beginning 5/18/06, all the gates were opened, and all the animals $(1-5)$ were able to physically interact with one another. On 6/8/06, animal 1 was separated from animals $2-5$. At facility B, animal 6 was paired with animals 8 and 10 , and animal 7 with animal 9 for the duration of the data collection period.

\section{Behavioral Recording and Analysis}

Animals 1 - 5 were monitored with continuous time stamped digital video recorded from an underwater viewing window using 3 Honeywell video surveillance cameras attached to a Honeywell digital recording device (Honeywell, Louisville, KY USA). Daylight video footage was analyzed (7 AM -6 PM) when the animal resided in the pool with the cameras, and amount of time the animals resided in the study pool each day ranged from $0-6 \mathrm{hrs}$. Video was downloaded and stored on an external hard drive (Maxtor OneTouch III 750GB Hard Drive, Seagate, Cupertino, CA USA).

Animals 6, 8, and 10 were videotaped from the surface for $1 \mathrm{hr}$ each day using a Canon HF200 HD camcorder (Canon USA Inc., Melville, NY) and footage downloaded onto an external hard drive (Seagate, Cupertino, California USA). Animals 7 and 9 were videotaped opportunistically from the surface using an iPhone 4S (Apple Inc, Cupertino, CA USA). All video footage was coded by the authors. 


\section{Proof of Ejaculation via the Identification of Spermatozoa in Vaginal Fluid}

Vaginal fluid was collected daily from animal 1 to identify spermatozoa indicating ejaculation had occurred. To collect vaginal fluid, the dolphin was partially pulled out of the water so that the genital slit was dry. First, the trainer stood on a dry ledge and grasped the tail flukes of the dolphin that was stationary in a dorsal position floating at the pool surface. The dry ledge was 7 to $10 \mathrm{~cm}$ higher than the water surface. Next, the trainer gently stepped backward pulling the dolphin's flukes backward and laterally over the ledge until the dolphin's genital slit was laterally out of the water. The dolphin's head and pectoral flippers remained in the water. The genital slit was wiped clean with gauze. The genital slit was gently spread apart using a gloved hand and a sterile 15.24-cm cotton tipped swab with a plastic shaft (Puritan Medical Products, Guilford, Maine, USA) was inserted $14 \mathrm{~cm}$ into the vaginal vault, twisted $360^{\circ}$, and removed. The swab was immediately rolled onto a $75 \mathrm{~mm}$ x $25 \mathrm{~mm}$ glass microscope slide and allowed to air dry for 24 hrs before reading. A phase contrast compound light microscope (LW Scientific, Lawrenceville, GA USA) at 400x power was used to analyze the slides. All slides were examined for the presence of spermatozoa by the author Muraco using previously published methods (Muraco, Coombs, Procter, Turek, \& Muraco, 2012).

\section{Results}

\section{Ultrasonography}

Ultrasound exams were conducted by the author Muraco using previously published methods (Muraco, Clough, Teets, Arn, \& Muraco, 2010) to identify the pre-ovulatory follicle (POF) and pregnancy in Animals 1, 6 and 7. For animal 1, a POF was identified on 5/27/06 on the left ovary and the follicle was gone on 6/8/06 indicating ovulation (Figs $1 \mathrm{a}$ and $\mathrm{b}$ ). Uterine fluid and a fetus were identified on 8/15/06 (Figure 1c). For animal 6, a POF was identified on 1/11/13 and a fetus on 4/3/13 (Figure 2a and $2 b$ ). For animal 7, a POF was identified on 2/3/14 and ovulation occurred on 2/4/14(Figure 3a and 3b). Uterine fluid and an embryo were identified on 4/7/14(Figure 3c).
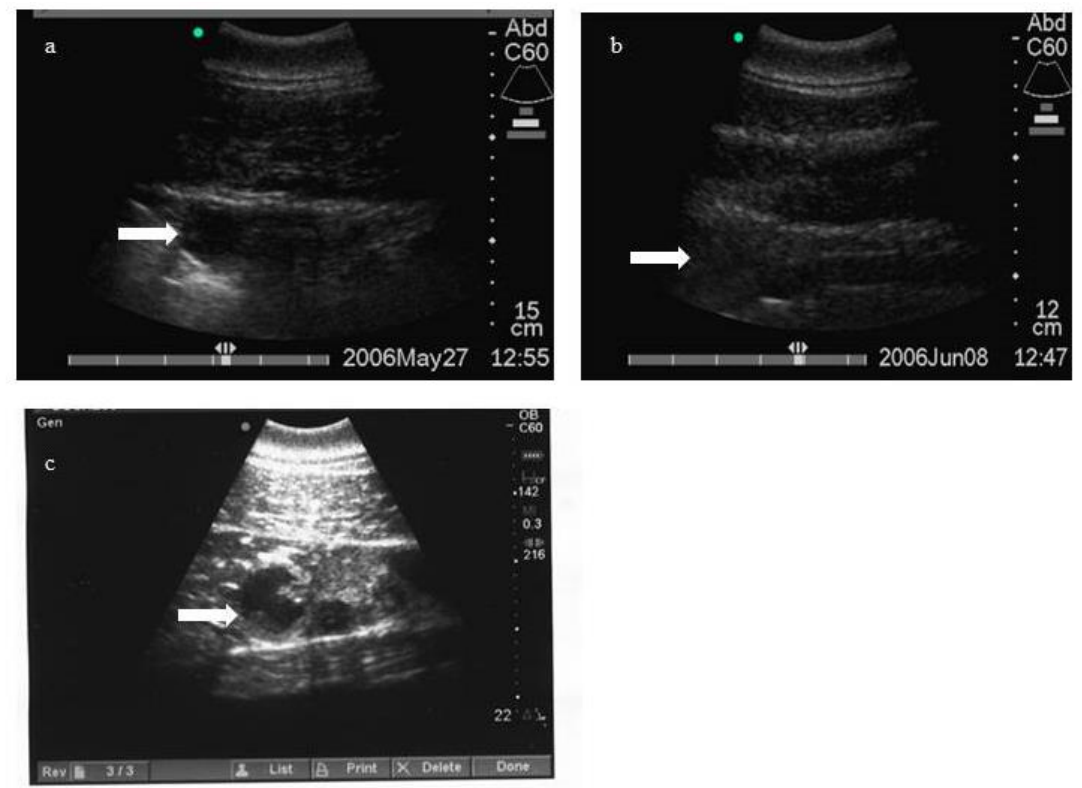

Figure 1. Animal 1 ultrasound. a) white arrow points to pre-ovulatory follicle, b) white arrow points to ovulated follicle, c) white arrow points to uterine fluid and embryo. 

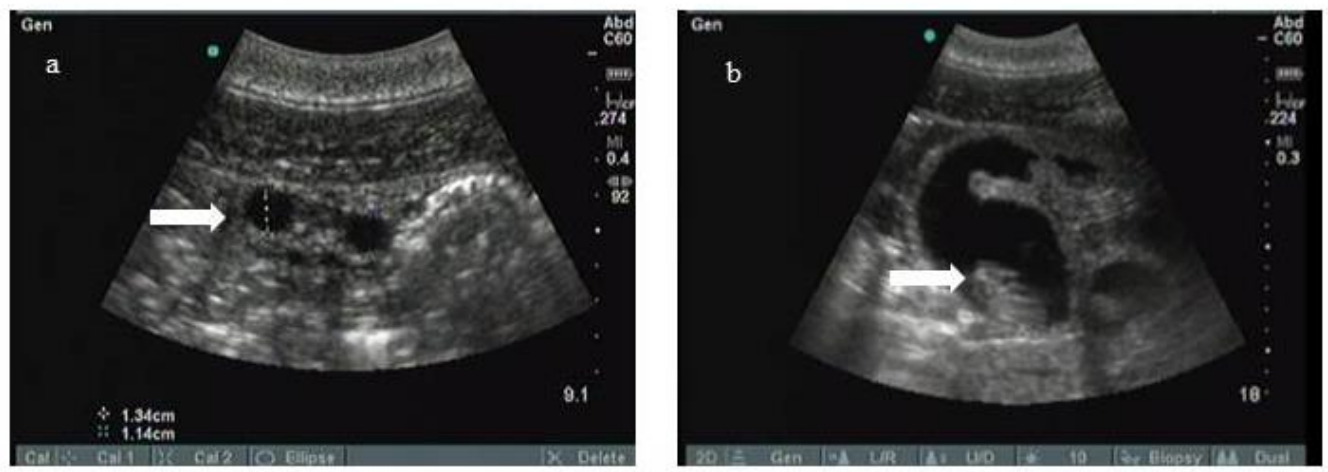

Figure 2. Animal 6 ultrasound. a) white arrow points to pre-ovulatory follicle, b) white arrow points to fetus.
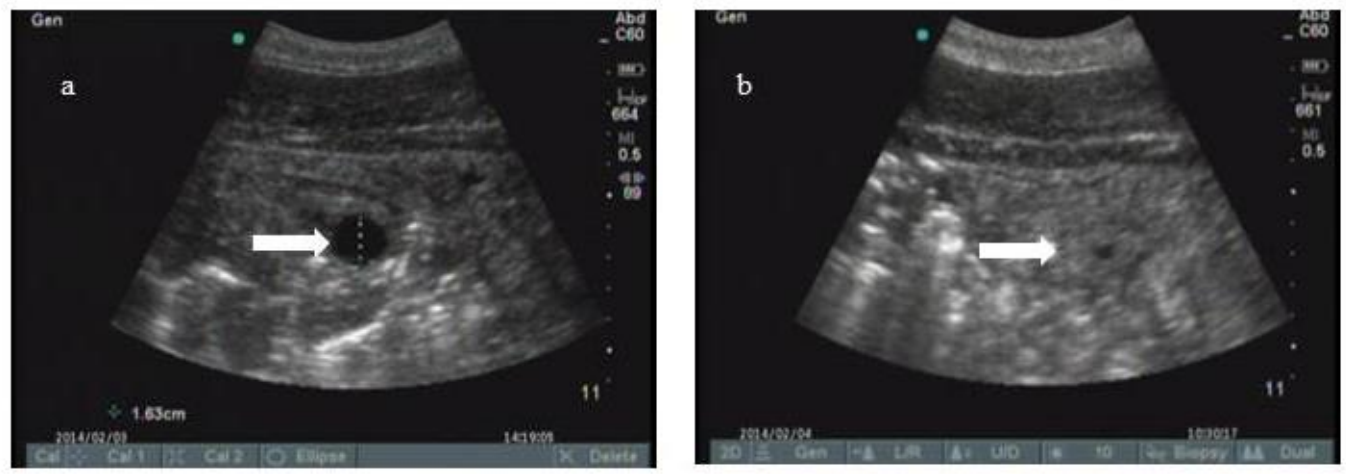

Figure 3. Animal 3 ultrasound. a) white arrow points to pre-ovulatory follicle, b) white arrow points to corpus hemorrhagic.

\section{Endocrinology}

Urine estradiol (uE2) and progesterone (uP) was tested in 28 samples surrounding social change, estrus, ovulation and pregnancy in animal 1 (Figure 4). In animal 1, LH was tested for 10 days, and the surge was identified in the am urine sample on 6/6/06. Ovulation occurred $24-36 \mathrm{hrs}$ later. Urinary progesterone was elevated $(>1.0 \mathrm{ng} / \mathrm{ml}) 14$ days following ovulation.

Urinary LH was tested in animals 6 and 7 to identify the LH surge. For animal 6, the LH surge was identified at 8 am on 1/13/13, and ovulation was assumed to have occurred $24-36 \mathrm{hrs}$ later based on previous studies (Muraco et al., 2010). For animal 7, ovulation (11 am 2/4/14) occurred 27 hours after the LH surge was identified (9 am 2/3/14).

\section{Reproductive Behavioral Ethogram}

Video recordings from animals 1-5, 6, 8 and 10, and 7 and 9 were analyzed to develop a reproductive behavioral ethogram. For animal 1, 22 days (49 total study hours) of underwater behavioral footage was analyzed $(2.227+/-1.602 \mathrm{hrs}$ daily) starting the day animals $1-4$ were introduced to animal 5 and ending when animal 1 was separated from the group following ovulation. For animal 6, 3 days (3 total study hours) of (above the surface) behavioral footage was analyzed ( $1 \mathrm{hr}$ daily) the day before the LH surge through the day of ovulation while she was paired with a mature male and nulliparous female (animals 8 and 10). Additionally, two minutes of underwater footage was taken of animals 6, 8 and 10 . Two days (4 min and $10 \mathrm{~min}$ ) of opportunistic (above the surface) behavioral footage and observations 
were conducted for animal 7 when she was paired with a mature female (Animal 9) the day before and of the LH surge.

For the ethogram, 20 focal reproductive behaviors were identified from 52 total hrs of recorded footage from animals $1-10$ (Table 2). Focal behaviors were selected after review of previously published dolphin ethograms and behavioral observations (Dudzinski, 1998; Furuichi et al., 2014; Puente \& Dewbury, 1976; Wells, 1984) and estrus behaviors of domestic hoofstock (Bearden et al., 2004; Helmer \& Britt, 1985).

Inter-rater reliability was $92.6 \%$.

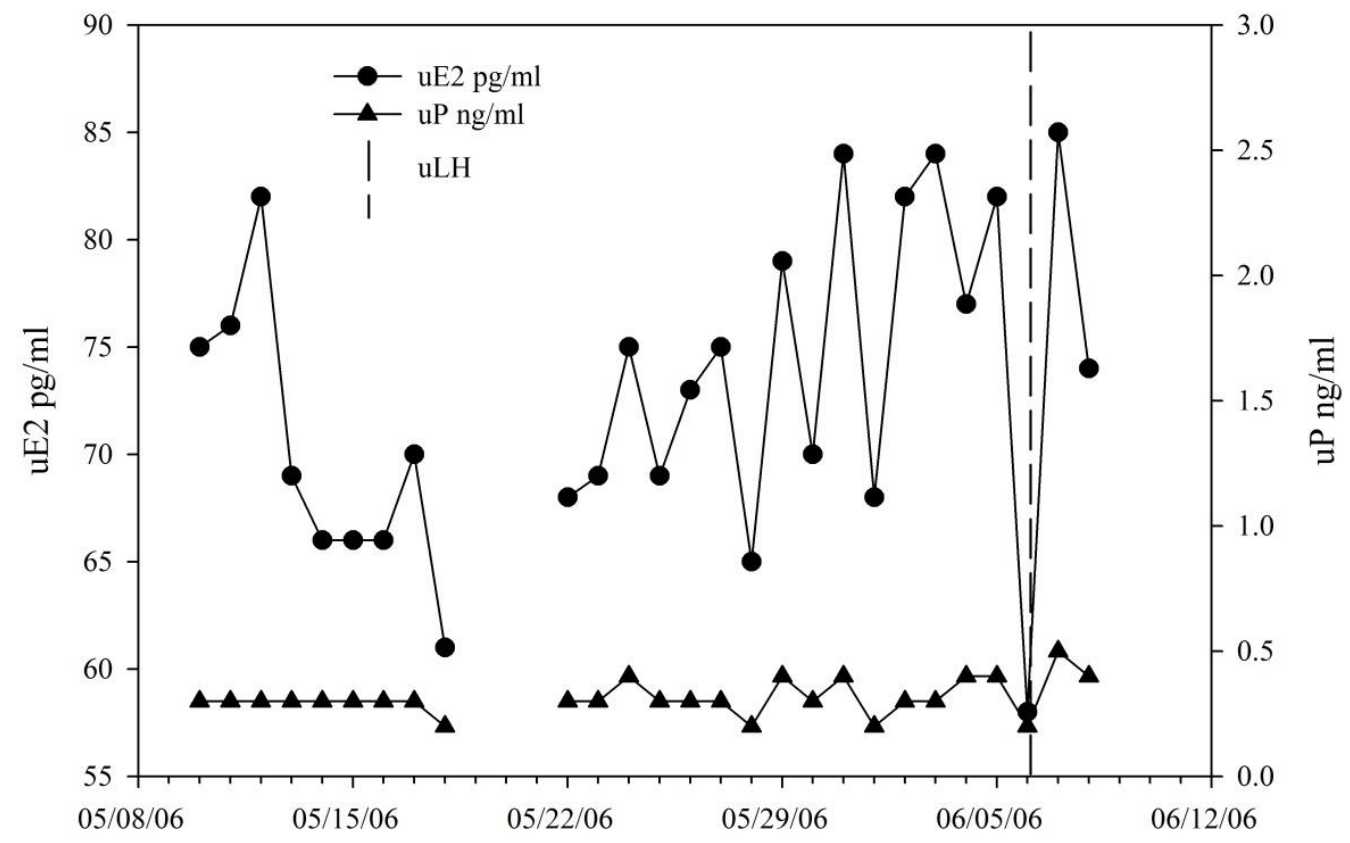

Figure 4. Animal 1 urinary estradiol, progesterone and luteinizing hormone.

\section{Reproductive State}

For animal 1 (Table 3), behaviors observed following the introduction to the mature male (days 21 through -16) were considered anestrus due to low levels of uE2, basal levels of uP, and no follicular development. Behaviors observed during days -15 through -12 were considered socio-sexual based on an increase in sexual behaviors and increasing $\mathrm{uE}$ levels but without the presence of sperm on the vaginal fluid slides. Days -11 through 0 are considered estrus based on elevated uE2 levels, copulatory behavior and the presence of sperm on the vaginal fluid slides. All sexual behaviors observed from animals 6 and 7 are considered estrus due to the close proximity to ovulation.

\section{All-Occurrences of Reproductive Behavior}

One hour each day (12 total hours) was analyzed for all-occurrences of reproductive behavior by or towards the focal multiparous female animal 1 (Table 3), three total hours were analyzed for animals 6 , 8 and 10, and 14 total minutes were analyzed for animals 7 and 9. Additionally, all-occurrences of atypical swimming patterns by the mature male, animal 5, were recorded. 
Table 2

Ethogram of Reproductive Behavior

\begin{tabular}{|c|c|c|}
\hline & Behavior & Description \\
\hline 1 & Avoid (A) & Female dolphin turns her genital slit away from a male dolphin (Figure 17) \\
\hline 2 & Copulation (COP) & Male dolphin thrusts penis into the genital slit of another dolphin (Figure 14) \\
\hline 3 & Dorsal Mount (DM) & One dolphin's dorsal fin goes into the genitals of another dolphin (Figure 13) \\
\hline 4 & Erection $(\mathrm{E})$ & Penis oriented towards another dolphin or object \\
\hline 5 & Fluke mount (FM) & One dolphin places a fluke into or against another's genital slit \\
\hline 6 & Flutter (FLU) & $\begin{array}{l}\text { Male dolphin performs an atypical swim pattern where the tail flukes are rapidly } \\
\text { moved up and down in a flutter-like motion }\end{array}$ \\
\hline 7 & Genital on head $(\mathrm{GOH})$ & Melon/head of a dolphin touches the genitals of another dolphin \\
\hline 8 & Genital tracking (GT) & $\begin{array}{l}\text { One dolphin swims so that the rostrum is oriented towards the genitals of another } \\
\text { without touching (Figure 11) }\end{array}$ \\
\hline 9 & Goose (GOS) & Rostrum touching a genital slit of another dolphin (Figure 12) \\
\hline 10 & Group-on-one-sex (GPS) & Two dolphins sexually thrust and rub on a single dolphin \\
\hline 11 & Immobility (IM) & $\begin{array}{l}\text { Dolphin remains immobile in a lateral or upright position at the surface, in the water } \\
\text { column or at the bottom of the pool for } 3 \text { or more seconds, often with eyes closed and } \\
\text { mouth slightly open (Figure } 6 \text { ) }\end{array}$ \\
\hline 12 & Line-up (LU) & $\begin{array}{l}\text { Three or more dolphins swim in a line with rostrums oriented towards the genital slit } \\
\text { often with lead dolphin slightly raising up tail fluke (Figure 15) }\end{array}$ \\
\hline 13 & Masturbate (MB) & $\begin{array}{l}\text { Single dolphin touches and rubs an object (i.e., toys) or structures in the environment } \\
\text { (i.e., filtration grates) on genitals }\end{array}$ \\
\hline 14 & Mount (MNT) & One dolphin positions themselves onto the back of another dolphin \\
\hline 15 & Pec mount (PMT) & One dolphin places pectoral fin into or against another's genital slit \\
\hline 16 & Pursuit (PUR) & Male dolphin quickly chases a female dolphin (Figure 16) \\
\hline 17 & Push (P) & One dolphin pushes another dolphin displaying immobility \\
\hline 18 & Rubbing (R) & Two or more dolphins rub one another with pectoral fins or body-to-body \\
\hline 19 & Shark (SRK) & $\begin{array}{l}\text { Male dolphin performs an atypical swim pattern where the peduncle and flukes move } \\
\text { left and right in a shark-like motion }\end{array}$ \\
\hline 20 & Thrust (THR) & An individual thrusts genitals towards another \\
\hline
\end{tabular}

Table 3

Animal 1 Reproductive Behavior, Endocrinology, Copulation, and Day of Cycle

\begin{tabular}{|c|c|c|c|c|c|c|c|c|c|}
\hline Date & $\mathrm{uE} 2^{\mathrm{a}}$ & $\mathrm{uLH}^{\mathrm{b}}$ & Repro $^{c}$ & Day $^{\mathrm{d}}$ & Sperm $^{\mathrm{e}}$ & Time $^{f}$ & Display $^{\mathrm{g}}$ & $\mathrm{P} \mathrm{Beh}^{\mathrm{h}}$ & $\mathrm{ABeh}^{\mathrm{i}}$ \\
\hline $5 / 18$ & 61 & & An & -21 & & $\begin{array}{l}1030- \\
1130\end{array}$ & & GT, PUR & GT, A \\
\hline $5 / 19$ & & & An & -20 & & $\begin{array}{l}1800- \\
1900\end{array}$ & SRK & GT & \\
\hline $5 / 20$ & & & An & -19 & & $\begin{array}{l}0600- \\
0700\end{array}$ & & PUR & $\mathrm{A}$ \\
\hline $5 / 21$ & & & An & -18 & & $\begin{array}{l}0900- \\
1000\end{array}$ & & & \\
\hline $5 / 22$ & 68 & & An & -17 & $\mathrm{~N}$ & & & & \\
\hline $5 / 23$ & 69 & & An & -16 & $\mathrm{~N}$ & $\begin{array}{l}1800- \\
1900\end{array}$ & $\begin{array}{l}\text { SRK } \\
\text { FLU }\end{array}$ & PUR & A \\
\hline $5 / 24$ & 75 & & S & -15 & $\mathrm{~N}$ & $\begin{array}{l}0700- \\
0800\end{array}$ & & GT & $\begin{array}{l}\text { GPS, DM, P, MNT, } \\
\text { THR, R, GT, FM }\end{array}$ \\
\hline $5 / 25$ & 69 & & S & -14 & $\mathrm{~N}$ & & & & \\
\hline $5 / 26$ & 73 & & $\mathrm{~S}$ & -13 & $\mathrm{~N}$ & & & & \\
\hline $5 / 27$ & 75 & & $\mathrm{~S}$ & -12 & $\mathrm{~N}$ & & & & \\
\hline $5 / 28$ & 65 & & $\mathrm{E}$ & -11 & $\mathrm{~N}$ & $\begin{array}{l}0900- \\
1000\end{array}$ & & R, GOS, GT & R, GOS, IM, THR, DM \\
\hline $5 / 29$ & 79 & & E & -10 & $\mathrm{~N}$ & & & & \\
\hline $5 / 30$ & 70 & - & $\mathrm{E}$ & -9 & $\mathrm{Y}$ & & & & \\
\hline $5 / 31$ & 84 & - & E & -8 & $\mathrm{Y}$ & $1800-$ & SRK & GT, GOS, COP, E, GOH, & IM, GT, GOS \\
\hline
\end{tabular}


Table 3 (cont.)

\begin{tabular}{|c|c|c|c|c|c|c|c|c|c|}
\hline $6 / 1$ & 68 & - & $\mathrm{E}$ & -7 & $\mathrm{Y}$ & $\begin{array}{l}1900 \\
930- \\
1030\end{array}$ & $\begin{array}{l}\text { FLU } \\
\text { FLU }\end{array}$ & $\begin{array}{l}\text { P, MNT, DM } \\
\text { LU, GT, R, GOH, PMT, } \\
\text { GOS, PUR }\end{array}$ & DM, IM, R, A \\
\hline $6 / 2$ & 82 & - & $\mathrm{E}$ & -6 & $\mathrm{~N}$ & $\begin{array}{l}0600- \\
0700\end{array}$ & & DM, GOS, GT, FM & R, DM, THR, IM \\
\hline $6 / 3$ & 84 & - & $\mathrm{E}$ & -5 & $\mathrm{Y}$ & & & & \\
\hline $6 / 4$ & 77 & - & $\mathrm{E}$ & -4 & $\mathrm{~N}$ & & & & \\
\hline $6 / 5$ & 82 & + & $\mathrm{E}$ & -3 & $\mathrm{Y}$ & & & & \\
\hline $6 / 6$ & 58 & + & E & -2 & $\mathrm{Y}$ & $\begin{array}{l}1700- \\
1800\end{array}$ & & $\mathrm{P}, \mathrm{GOS}$ & IM \\
\hline $6 / 7$ & 85 & - & $\mathrm{E}$ & -1 & $\mathrm{Y}$ & & & & \\
\hline $6 / 8$ & 74 & - & $\mathrm{E}$ & 0 & $\mathrm{~N}$ & $\begin{array}{l}0700- \\
0800\end{array}$ & & $\begin{array}{l}\text { DM, THR, MNT, GT, P, } \\
\text { COP }\end{array}$ & $\begin{array}{l}\text { GT, GOS, THR, IM, } \\
\text { DM }\end{array}$ \\
\hline
\end{tabular}

a. urinary estradiol $\mathrm{pg} / \mathrm{ml}$

b. urinary luteinizing hormone positive or negative

c. reproductive state

d. day of cycle

e. sperm on vaginal fluid slides yes or no

f. time of day behavior was recorded

g. display by mature male

h. passive behavior

i. active behavior

Results below are presented as the name of the behavior followed by the number of occurrences in parenthesis.

\section{Active Reproductive Behaviors by Animal 1 (Figure5)}

Anestrus. Active behaviors by the focal female (animal 1) that were oriented towards the mature male (animal 5) following the introduction and during anestrus included avoid (3) and genital tracking (2), and no behaviors were observed by the multiparous female towards animals $2-4$. In total, 5 behaviors were oriented towards the mature male during anestrus with avoid being most frequent.

Socio-Sexual. No behaviors were oriented towards the mature male or immature female (animal 3 ) during the socio-sexual period. Behaviors towards the immature male (animal 4) included genital tracking (1), group-on-one sex (1), dorsal mount (3), push (1), mount (1), thrust (1), rub (1), and fluke mount (1). Behaviors towards the nulliparous mature female (animal 4) included group-on-one sex (1). In total, 10 behaviors were oriented towards the immature male and 1 towards the nulliparous female. Dorsal mount was the most frequent.

Estrus. No behaviors were oriented towards the immature female during estrus. Behaviors towards the mature male included avoid (2), genital tracking (1), goose (1), and copulation (2). Behaviors towards the nulliparous mature female included dorsal mount (12), genital tracking (1), thrust (5), rub (5) and goose (3). Behaviors towards the immature male included dorsal mount (1). In total, 6 behaviors were oriented towards the mature male, 26 towards the nulliparous female and 1 towards the immature male. Dorsal mount was the most frequent.

\section{Passive Behaviors Towards Animal 1 (Figure5)}

Anestrus. No behaviors were oriented towards the focal female by animals $2-4$ during anestrus. Behaviors by the mature male towards the focal animal following the introduction and during anestrus included pursuit (3) and genital tracking (2). In total, 5 behaviors were oriented towards the focal animal by the mature male with pursuit being the most frequent. 
Socio-Sexual. No behaviors were oriented towards the focal female by the mature male, the immature female or the nulliparous female during the socio-sexual period. Behaviors by the immature male towards the focal female during the socio-sexual period included genital tracking (2). In total, 2 genital tracking behaviors were orientated towards the focal female by the immature male.

Estrus. Behaviors by the mature male towards the focal female during estrus included pursuit (2), genital tracking (6), goose (1), push (1), mount (1), genital-on-head (1), erection (2), line-up (1) and copulation (2). Behaviors by the immature male towards the focal female included genital tracking (3) and goose (1). Behaviors by the nulliparous female towards the focal female included genital tracking (5), goose(13), dorsal mount (34), push (1), mount (2), thrust (2), rub (4), fluke mount (1), pec mount (1), and genital-on-head (1). No behaviors were oriented towards the focal female by the immature female. In total, 17 behaviors were oriented towards the focal female by the mature male, 4 by the immature male, and 64 by the nulliparous female. Dorsal mount was the most frequent.
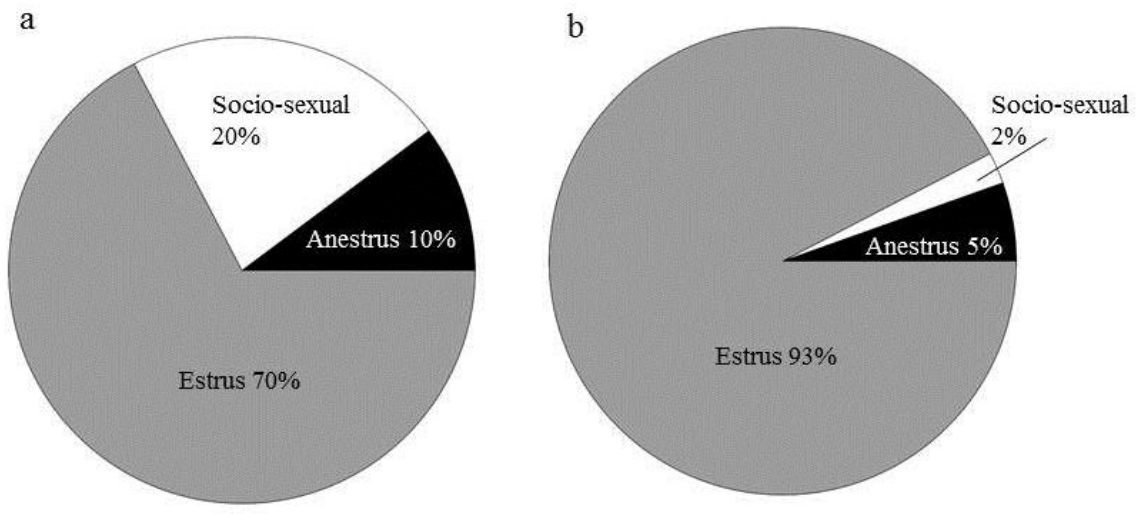

Figure 5. Percentage of reproductive behaviors during each reproductive phase for animal 1. a) active, b) passive.

\section{Active Reproductive Behaviors by Animals 6 and 7}

Behaviors enacted by the focal nulliparous female (animal 6) towards the mature male (animal 8) included avoid (41) and copulation (6). Behaviors by animal 6 towards the nulliparous female (animal 10) included rub (1) and towards toys included masturbate (6). In total, 47 behaviors were orientated towards the mature male by the focal female and 1 towards the nulliparous female.

Behaviors enacted by the focal nulliparous female (animal 7) towards the multiparous pregnant female (animal 9) included genital tracking (1), genital-on-head (1) and goose (1). In total, 3 behaviors were orientated towards the pregnant female by the focal nulliparous female.

\section{Passive Reproductive Behaviors by Animals 6 and 7}

Behaviors by the mature male towards the focal nulliparous female (animal 6) included pursuit (48), push (16), genital tracking (2), copulation (6), mount (6), goose (1), line-up (1), and erection (1). In total, 81 behaviors were orientated towards the focal nulliparous female by the mature male and 0 by the nulliparous female. Avoid and pursuit was the most frequent.

Behaviors from animal 9 towards animal 7 included push (1).

\section{Immobility}

All three focal females (animals 1, 6 and 7) demonstrated bouts of immobility (IM) during which they became motionless in the water, often with eyes closed and mouth open (Figure 6). This behavior 
occurred when the animal was alone (i.e., not in close proximity of any other dolphins) as well as when interacting with other dolphins. The behavior was observed to occur throughout the water column from the surface to the bottom of the pool and in both vertical and horizontal positions.

Animal 1 demonstrated immobility 31 times between 5/28/06 and 6/8/06 (6 hrs) totaling $397 \mathrm{~s}$ (Figure 7), with the longest continuous immobility bout being 34 s. Animal 6 demonstrated immobility 20 times between $1 / 12 / 13$ and 1/14/13 ( 3 hours) totaling $247 \mathrm{~s}$ with the longest continuous immobility bout being $34 \mathrm{~s}$. Animal 7 demonstrated immobility 12 times between 2/2/14 and 2/3/14 (14 min) totaling 502 $\mathrm{s}$ with the longest continuous immobility bout being $150 \mathrm{~s}$.

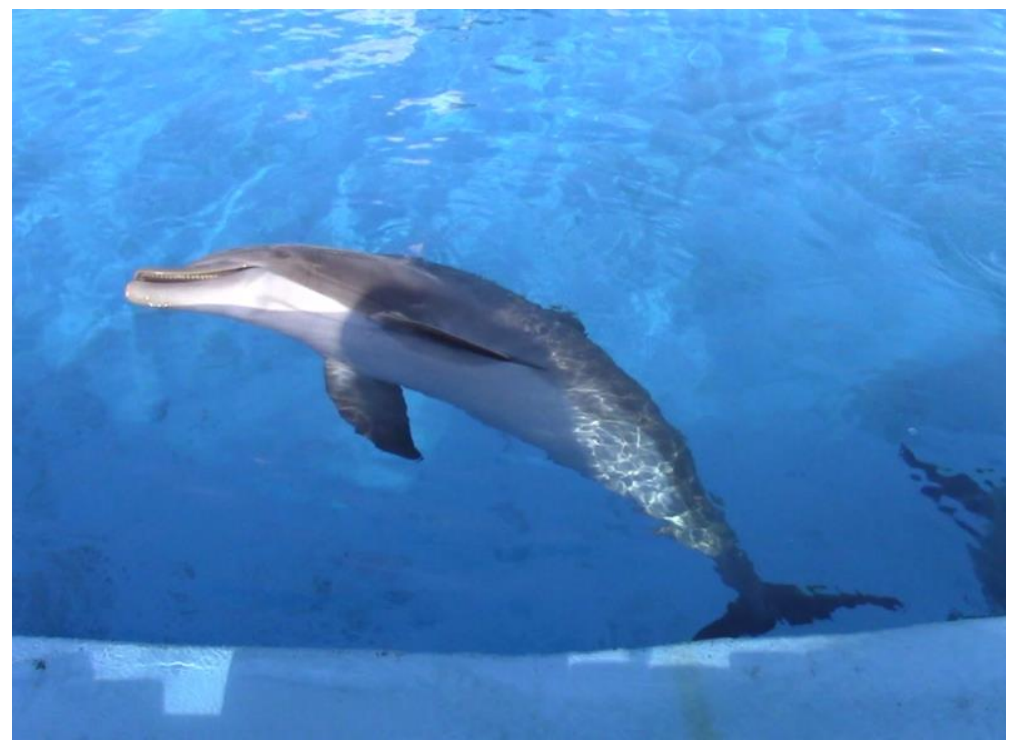

Figure 6. Immobility (IM) behavior, lateral with eyes closed and mouth slightly open.

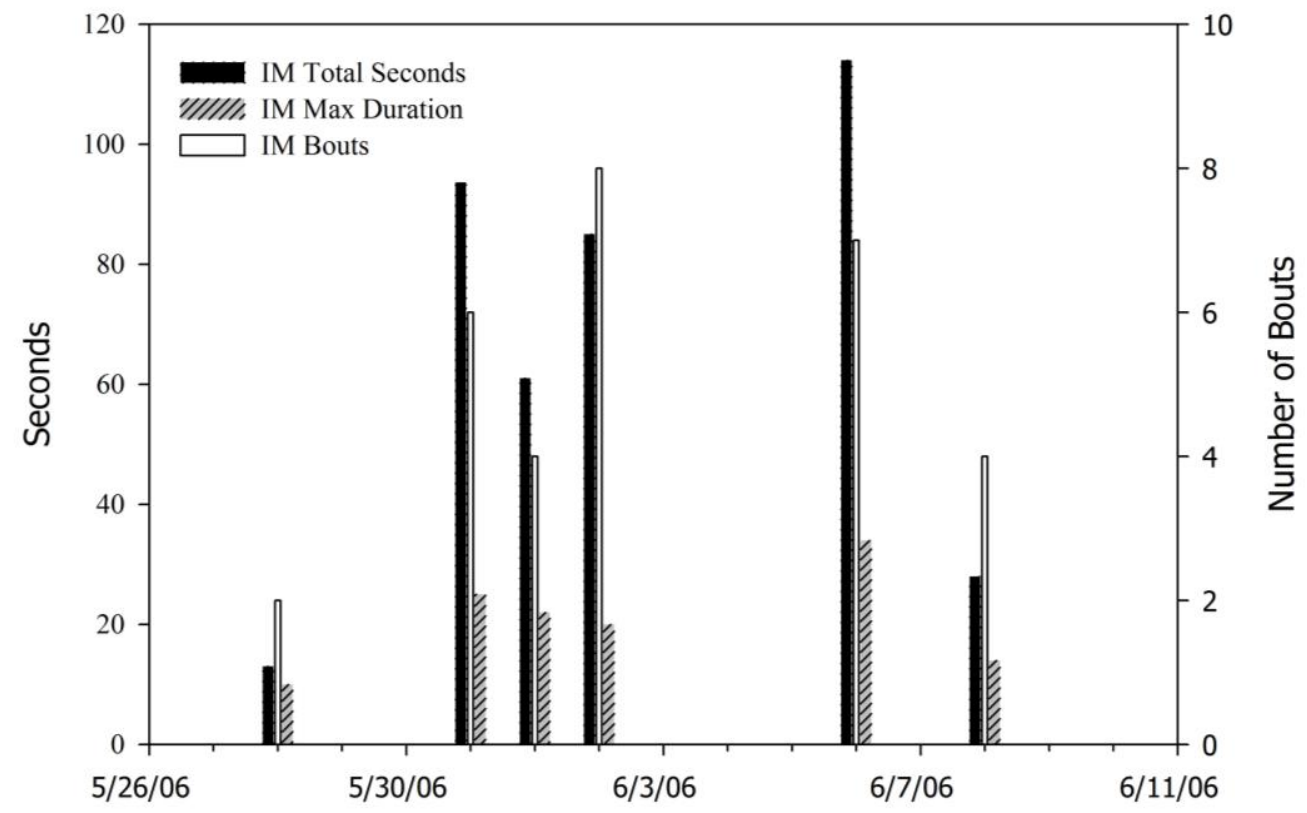

Figure 7. Animal 1 immobility bouts, total duration in seconds and maximum bout duration in seconds. 


\section{Behavioral Correlations to Endocrinology}

Estradiol. Urinary E2 levels and the combined total number of reproductive behaviors by and towards the focal female (animal 1) during each reproductive state were compared (Table 4). A trend was observed showing an increase in the number of sexual behaviors as mean uE2 levels rose (Figure 8).

Table 4

Animal 1 Number of Reproductive Behavioral Occurrences and uE2 Levels

\begin{tabular}{llll}
\hline Repro State & Beh Oc $^{\mathrm{a}}$ & Mean uE2 pg/ml & Max uE2 pg/ml \\
& & & \\
\hline Anestrus & 10 & $66.00+/-2.517^{\mathrm{b}}$ & 69.00 \\
Socio-Sexual & 13 & $73.00+/-1.414^{\mathrm{c}}$ & 75.00 \\
Estrus & 118 & $75.667+/-2.521^{\mathrm{d}}$ & 85.00 \\
\hline
\end{tabular}

a. combined active and passive behavioral occurrences

b. 3 samples tested

c. 4 samples tested

d. 12 samples tested

Luteinizing Hormone (LH). Total bouts of the immobility behavior (IM) reached maximum numbers during the LH surge in all three focal females (animals 1, 6 and 7) (Figure 8 and 9).

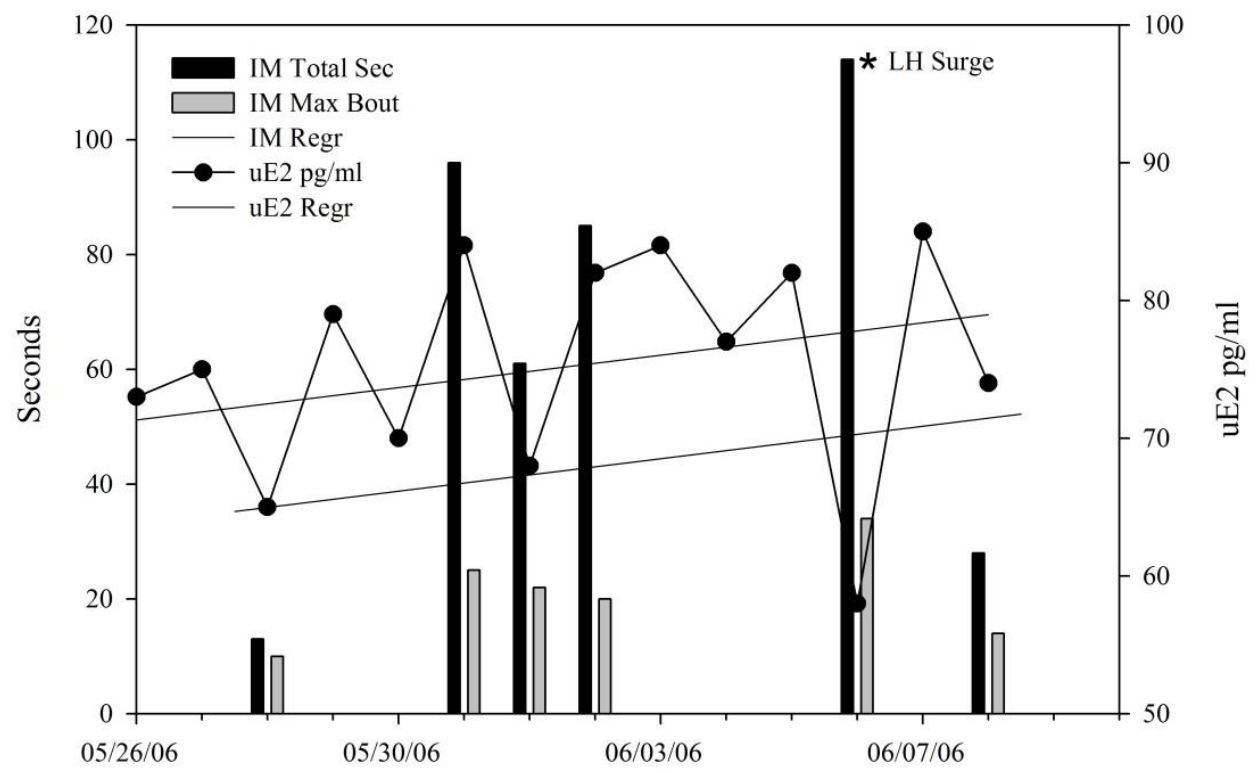

Figure 8. Animal 1 immobility, uE2, uLH and regression. 


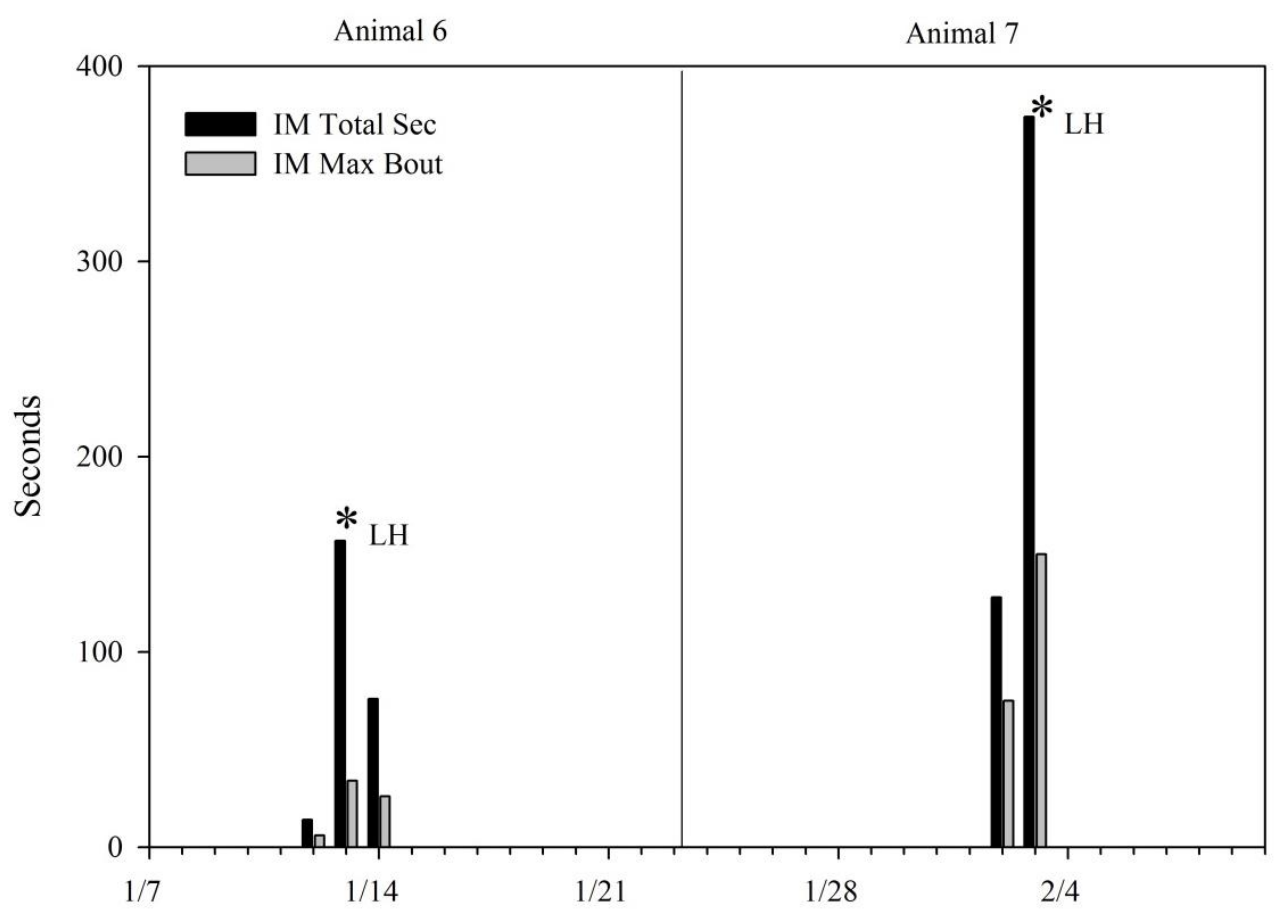

Figure 9. Animals 6 and 7 immobility duration and uLH correlation.

\section{Copulation Observations and Spermatozoa in Vaginal Fluid}

Only two copulations $(5 / 31 / 06,6 / 8 / 06)$ were observed in 12 hours of behavioral footage between animals 1 and 5, however vaginal fluid collected for 18 consecutive days (5/22/06 - 6/8/06) showed spermatozoa on 7 days between 5/30/06 and 6/7/06 (Table 3). The copulation on 5/31/06 started with the male genital tracking the female, the female showing immobility, the male goosing the female, followed by copulation occurring with the animals' perpendicular to one another near the water's surface. The copulation on 6/8/06 started with the female (animal 1) immobile and the nulliparous female (animal 2) pushing, dorsal mounting, thrusting and mounting animal 1 . The male (animal 5) was nearby and swam in and copulate with animal 1 who was immobile.

Surface behavioral recordings revealed six copulations between animal 6 and 8. Each successful copulation was preceded by a similar pattern in which the female was in a lateral surface immobility position, the male approached and genital tracked, goosed or pushed, followed by copulation near the surface with the animals perpendicular to one another (Figure 14). During unsuccessful copulation attempts the male would pursue a female that was not demonstrating the immobility behavior, and she would avoid his pursuits by turning her genital slit away from him or swimming away.

\section{Mature Male (Animal 5) Display}

The mature male (animal 5) demonstrated two distinct types of atypical swimming patterns, shark and flutter which appeared to be used as a form of courtship display. The shark swim pattern included the male moving the peduncle and tail flukes in a side-to-side motion. The flutter involved moving the tail flukes up and in down rapidly without a proportional forward momentum. 
On $5 / 19 / 06$, the day after the introduction of the focal female (animal 1) to the mature male (animal 5), the male swam under the focal female and genital tracked. Immediately after the genital tracking, the male swam in a shark-like motion in front of the focal female (animal 1).

On 5/23/06, two atypical swim patterns were observed. The first involved the immature male (animal 4). The immature male swam around the mature male (animal 5) who was positioned vertically in the water column. The mature male performed the shark swim pattern while vertical in the water column. The second atypical swim pattern involved the focal female. The mature male genital tracked the focal female, and the focal female responded by avoiding the male; the male then positioned himself horizontally near the water surface and swam in a flutter-like motion.

On 5/31/06, two atypical swim patterns were observed. The first occurred when the male swam under and in front of the focal female and swam in the shark swim pattern. The second occurred when the mature male genital tracked the focal female followed by the focal female showing immobility. The male swam in a flutter-like motion near the water's surface, and seven seconds later copulation occurred.

On 6/1/06, one atypical swim pattern was observed. The mature male genital tracked the focal female, and the female avoided the male. The male then positioned himself near the surface of the water and swam in a flutter-like motion.

\section{Discussion}

Our intent was to define reproductive behaviors in dolphins of known reproductive states and identify behaviors that could be exclusive to estrus. Dolphins evolved from artiodactyls (even-toed ungulates including cows, pigs hippos and camels) (Milinkovitch \& Thewissen, 1997), and because of the monophyletic grouping of cetaceans and artiodactyls, a dolphin is more closely related to a cow than a horse is. Perhaps some terrestrial reproductive processes have been conserved in the dolphin that we can use to improve our understanding of this species. For the purposes of this study, the estrus period was defined as the period between the female first exhibiting immobility until ovulation, and this is similar to what is accepted as the criteria for the estrus period in cattle (Helmer \& Britt, 1985). Estrus duration and the timing of ovulation after the start of estrus is species dependent, varies from one female to another, and differs with nulliparous or parous animals. In cows, estrus lasts from $\sim 18-19 \mathrm{hrs}$ with ovulation occurring 10 - $11 \mathrm{hrs}$ after estrus end; in the sow, estrus lasts $48-72 \mathrm{hrs}$ with ovulation occurring $35-45$ hrs from the beginning of estrus; and in the mare, estrus lasts $4-8$ days with ovulation occurring $1-2$ days before estrus end (Hafez \& Hafez, 2000). The average follicular and luteal phase for a dolphin lasts 10 and 20 days respectively (Muraco et al., 2010). There was an increase in reproductive behavioral occurrences during estrus as estradiol and luteinizing hormone levels peaked, which is consistent with patterns in domestic species (Austin \& Short, 1972; Bearden et al., 2004; Hunter, 1980; Pineda \& Dooley, 2003). In the dominant, multiparous dolphin (animal 1), estrus spanned the duration of the 10 day follicular phase and peak behaviors occurred during the LH surge. She primarily sexually interacted with the nulliparous mature female during her estrus period with active and passive dorsal mounting seen most frequently. In the nulliparous, sub-dominant female (animal 6), copulation was only successful during LH and ovulation periods when the female displayed immobility. When not engaged in sexual interactions with the mature, dominant male (animal 8), she was observed masturbating with toys.

Two unique behaviors observed in the study were genital tracking and immobility. The genital tracking behavior was first observed upon introduction of the female 1 to the mature male 5 with the behavior increasing in frequency during estrus. The genital tracking behavior is similar in appearance to "genital sniffing" behavior observed in terrestrial mammals, and it is possible that dolphins may utilize chemosensory abilities for reproduction. Studies conducted by the United States Navy showed that dolphins have the ability to distinguish salty, sweet, sour and bitter, with most sensitivity to bitter (Nachtigall, 1986; Nachtigall \& Hall, 1984), and Russian scientists hypothesized that dolphins may use taste reception in a form of chemically-mediated communication (Kuznetsov, 1990; Yablokov, 1961). Perhaps dolphins are able to gain information about another dolphin's physiological state via a form of chemo-communication. Although it is possible that the dolphins were looking at the genital slit to gain a 
visual cue, there was no obvious change, such as swelling, observed at any point in the study. The genital slit occasionally turned a light shade of pink following bouts of rubbing, but since dolphins are colorblind (Peichl, Behrmann, \& Kröger, 2001), this would not work well as a visual cue. There was no evidence in this study that the dolphins were echolocating on the genital slit when engaged in genital tracking, although no audio recordings were formally analyzed. The genital tracking behavior often progressed to the goose behavior, which is similar in appearance to "vulva nuzzling" observed in terrestrial mammals. The goose behavior has been reported as part of dolphin socio-sexual repertoires (Dudzinski, 1998), and it has been observed in adult females towards their offspring (Figure 10) (Ridgway, 1972).

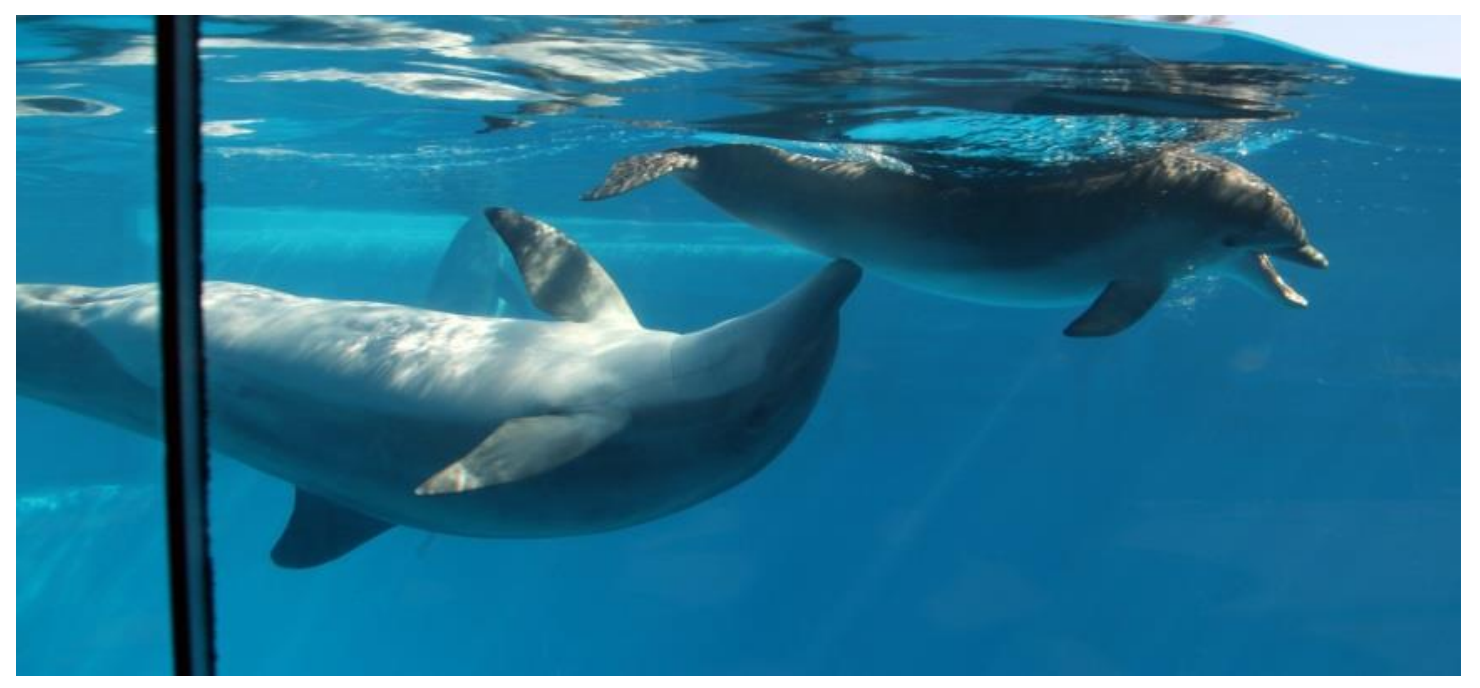

Figure 10. A dolphin mother gooses her 3 month old female calf.

The immobility behavior was observed in all three focal females during estrus, and maximum immobility duration occurred during the LH surge. The estrous cycle is regulated by endocrine and neuroendocrine mechanisms including hypothalamic hormones, gonadotropins and gonadal steroids (Bearden et al., 2004; Hafez \& Hafez, 2000). Luteinizing hormone-releasing hormone (LHRH) is primarily responsible for the ovulatory surge of LH and facilitation of lordosis (estrus) in rats (Foreman \& Moss, 1979; Moss \& McCann, 1975; Moss \& Foreman, 1976; Pfaff, 1973), and in sows, maximum LH levels being present at the first observance of behavioral estrus (Tilton, Foxcroft, Ziecik, Coombs, \& Williams, 1982). Bottlenose dolphins have pre-ovulatory LH surges that last 12-24 hours with peak levels lasting 6 hrs, and ovulation following peak LH levels within $24-48$ hrs (Muraco et al., 2010). In this study, immobility occurred prior to or during each observed copulation which suggests that dolphins demonstrate a novel form of lordosis and/or standing heat estrus that assists in copulation success. The genital tracking and goose behaviors may serve to communicate reproductive readiness (or lack thereof), while immobility demonstrates copulatory receptivity.

The dominant female (animal 1) demonstrated a period of active socio-sexual behavior with the immature male following anestrus and prior to estrus. Her estradiol levels were above anestrus levels during this time period which may have contributed to the behavior. However, she was observed aggressively herding the immature male away from the mature male, so the socio-sexual behavior may have been a display of dominance. Unlike the gonadal steroid estrogen, and the protein hormone LH, which contribute to conceptive estrus behavior (Foreman \& Moss, 1979; Moss \& McCann, 1975; Moss \& Foreman, 1976; Pfaff, 1973), socio-sexual behavior can be mediated by oxytocin (Carter, 1992; Kendrick et al., 2000). Oxytocin is a nonapeptide produced primarily in the supraoptic (SON) and paraventricular (PVN) nuclei of the hypothalamus (Carter, 1992). Pulses of oxytocin are released into systemic circulation from the posterior pituitary following tactile stimulation in rats and during sexual arousal in 
humans (Carter, 1992). It is probable that oxytocin may be responsible for the highly tactile socio-sexual interactions of dolphins, while estrogen and LH contribute to estrus behaviors.

Finally, the proven sire (animal 5) demonstrated atypical swim patterns that appeared to act as a form of display or courtship. The male (animal 5) was new to the social group where the focal female (animal 1) was dominant. He was observed displaying the unusual swim patterns in several contexts: (1) following the introduction to the focal female, (2) after the focal female demonstrated avoidance behavior, and (3) once prior to copulation.

Encountering sexual partners though mutual searching, identification of physiological states and sequential interactions that result in copulation are essential steps to ensure the survival of any species, and we have a fairly clear understanding of terrestrial animal reproductive biology, behavior and ecology. However, the holaquatic world of the dolphin remains steeped in mystery, and our knowledge of reproduction in Cetacea is rudimentary at best. Future studies should focus on sex hormones, oxytocin levels and behavior during non-conceptive socio-sexual scenarios, conceptive estrus cycles, and male courtship displays to help determine the relative roles of these variables on dolphin reproductive behavior.

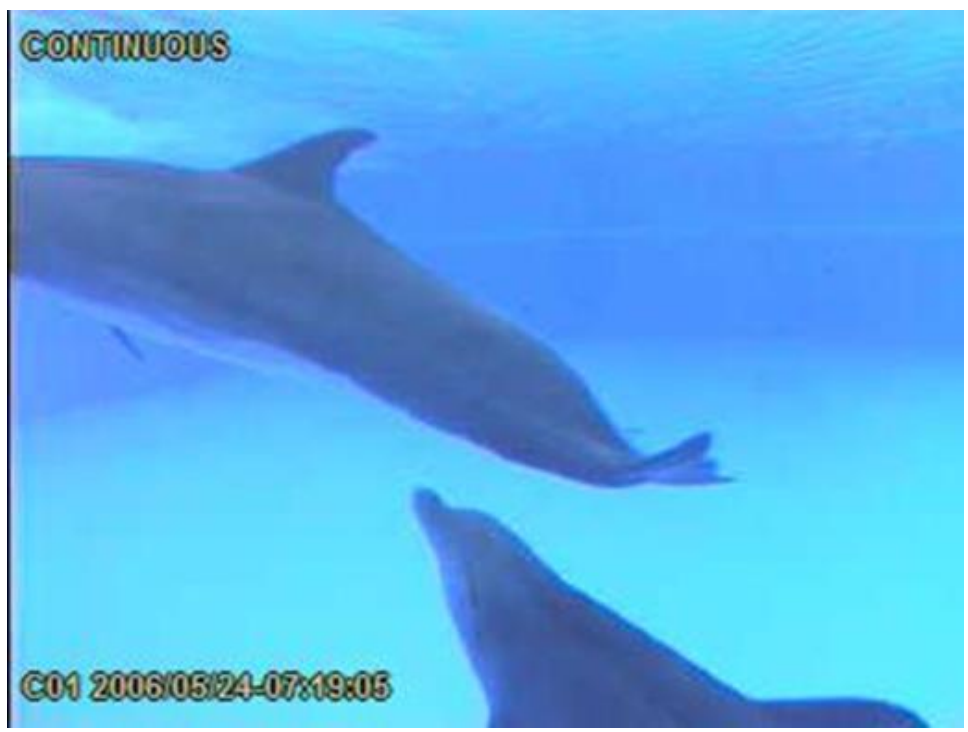

Figure 11. Genital tracking (GT) of animal 1 by animal 4.

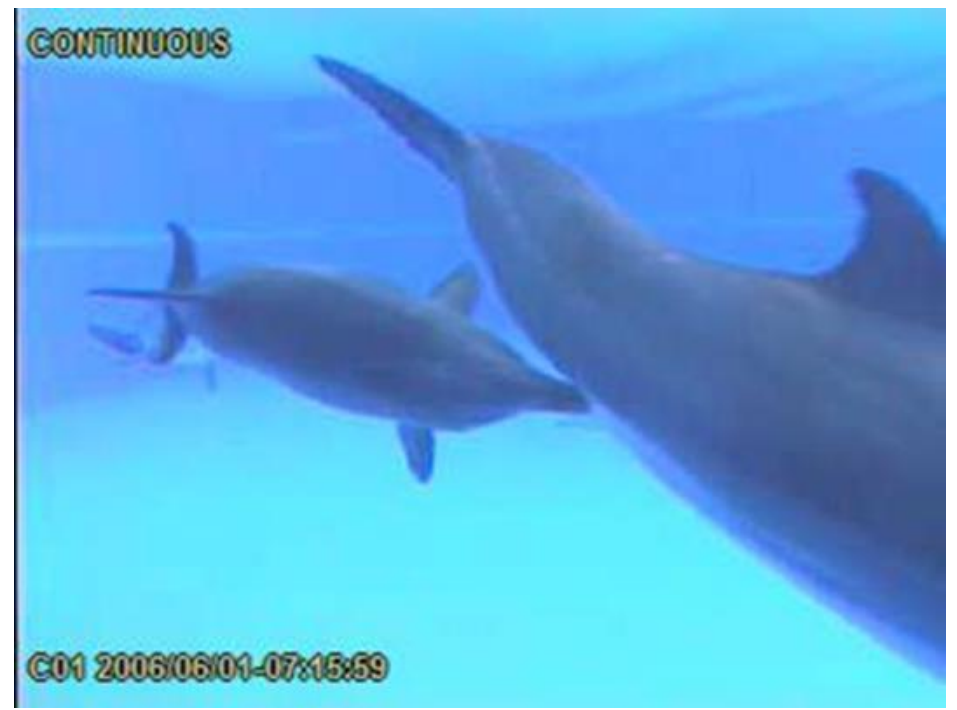

Figure 12. Goose (GOS) of animal 1 by animal 4. 


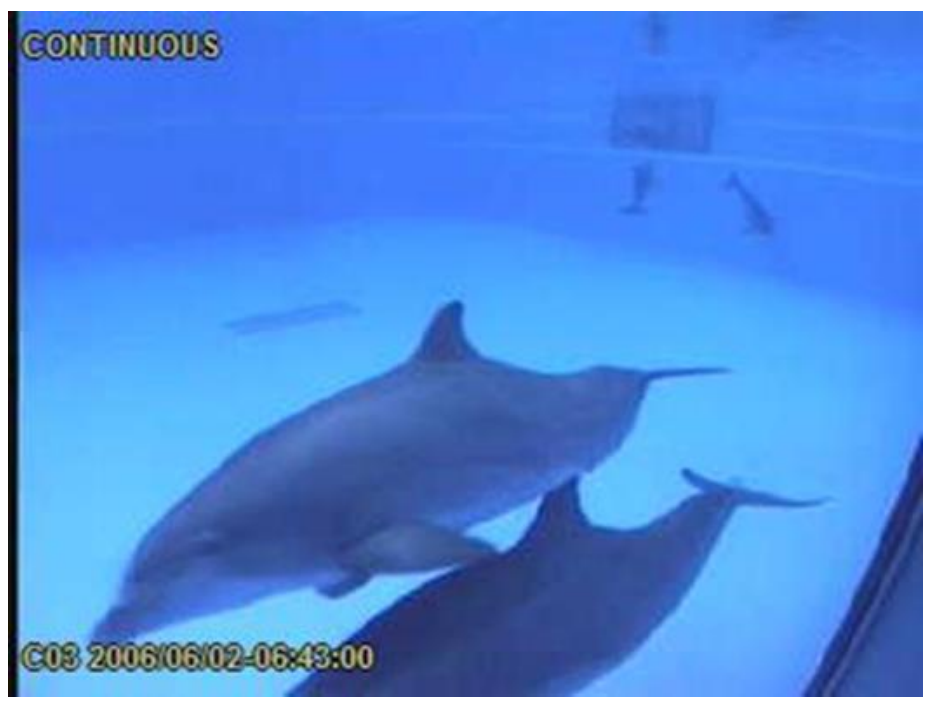

Figure 13. Dorsal Mount (DM) of animal 1 by animal 2.

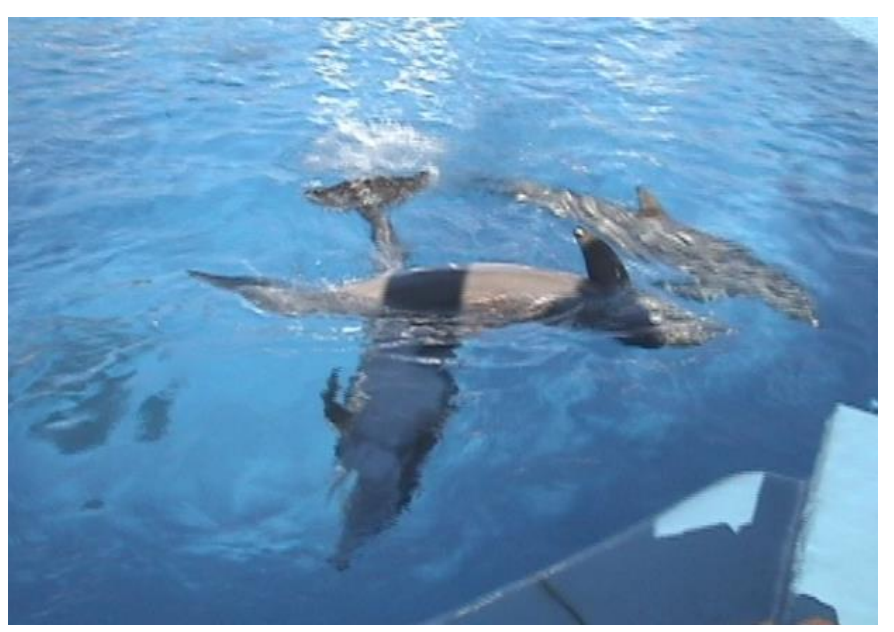

Figure 14. Copulation (COP) between animal 8 and animal 6.

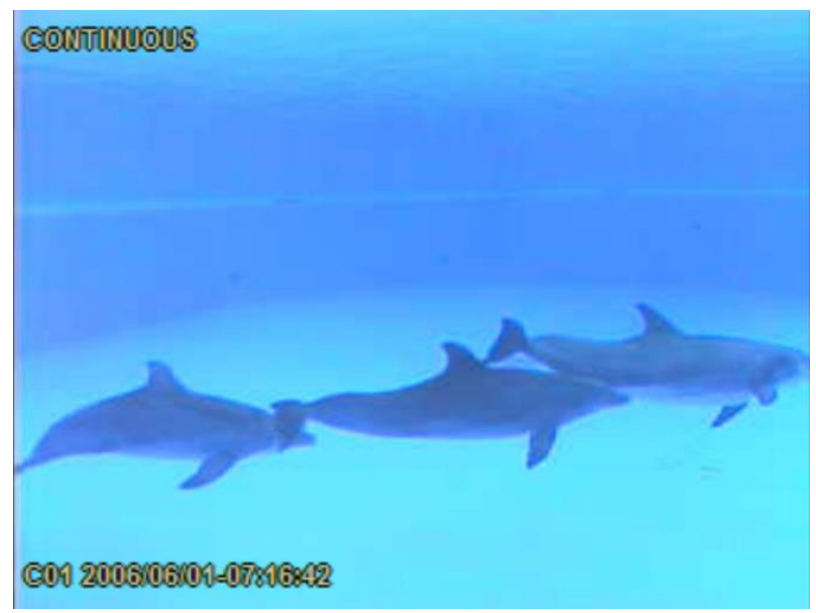

Figure 15. Line Up (LU) animal 1 at the front with animals 4 and 5 behind. 


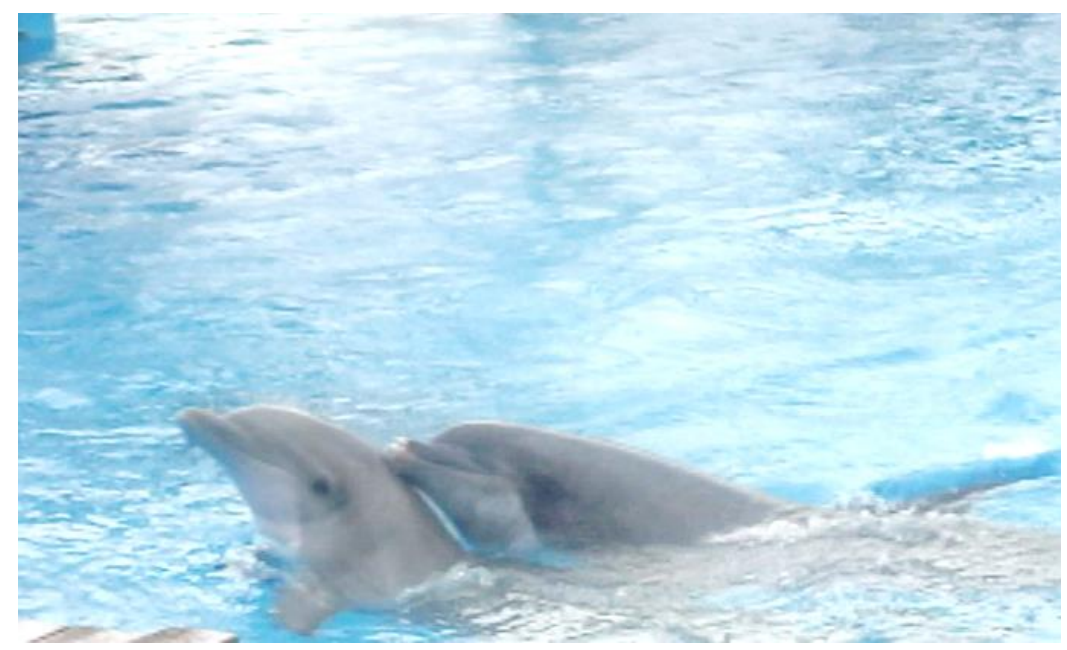

Figure 16. Mount (MNT) by animal 8 to animal 6.

\section{References}

Austin, C., \& Short, R. (Eds.) (1972). Reproductive Patterns in Reproduction in mammals. (Vol. 4, pp. 34-54). Cambridge, NY: Cambridge University Press.

Bearden, H., Fuquay, J., \& Willard, S. (Eds.)(2004). Mating Behavior in Applied animal reproduction, 6th ed. (pp. 87 - 95). Upper Saddle River, NJ: Pearson Prentice Hall.

Carter, C. S. (1992). Oxytocin and sexual behavior. Neuroscience \& Biobehavioral Reviews, 16, 131-144.

Connor, R. C., Smolker, R. A., \& Richards, A. F. (1992). Two levels of alliance formation among male bottlenose dolphins (Tursiops sp.). Proceedings of the National Academy of Sciences, 89, 987-990.

Dudzinski, K. M. (1998). Contact behavior and signal exchange in Atlantic spotted dolphins (Stenella frontalis).Aquatic Mammals, 24, 129-142.

Foreman, M. M., \& Moss, R. L. (1979). Role of hypothalamic dopaminergic receptors in the control of lordosis behavior in the female rat. Physiology \& Behavior, 22, 283-289.

Furuichi, T., Connor, R., \& Hashimoto, C. (2014). Non-conceptive sexual interactions in monkeys, apes, and dolphins. In Primates and cetaceans (pp. 385-408). Tokyo, Japan: Springer.

Hafez, E., \& Hafez, B. (Eds.) (2000). Anatomy of Female Reproduction in Reproduction in farm animals, 7th ed. (pp. 59-67). Baltimore, Maryland: Lippincott Williams and Wilkins.

Hanby, J. P., \& Brown, C. E. (1974). The development of sociosexual behaviours in Japanese macaques Macaca fuscata. Behaviour, 49,152-196.

Hunter, R. (Ed.) (1980). The Estrous Cycle in Physiology and technology of reproduction in female domestic animals (pp. 19-21). New York: Academic Press.

Kuznetzov, V. B. (1990). Chemical sense of dolphins: Quasi-olfaction in Thomas, J \& Kastelein, R. (Eds.) Sensory abilities of cetaceans (pp. 481-503). New York, NY: Plenum Press.

Milinkovitch, M. C., \& Thewissen, J. G. M. (1997). Evolutionary biology: Even-toed fingerprints on whale ancestry. Nature, 388, 622-623.

Moss, R., \& Foreman, M. (1976). Potentiation of lordosis behavior by intrahypothalamic infusion of synthetic luteinizing hormone-releasing hormone. Neuroendocrinology, 20, 176-181.

Moss, R. L., \& McCann, S. M. (1975). Action of luteinizing hormone-releasing factor (LRF) in the initiation of lordosis behavior in the estrone-primed ovariectomized female rat. Neuroendocrinology, 17, 309-318.

Muraco, H. S., Coombs, L. D., Procter, D. G., Turek, P. J., \& Muraco, M. J. (2012). Use of human chorionic gonadotropin in a male Pacific walrus (Odobenus rosmarus divergens) to induce rut and achieve a pregnancy in a nulliparous female. Journal of Andrology, 33, 789-797. doi: 10.2164/jandrol.111.015032

Muraco, H., Clough, P., Teets, V., Arn, D., \& Muraco, M. (2010). Ovarian follicular dynamics during the luteinizing hormone surge in the bottlenose dolphin (Tursiops truncatus). International Journal of Comparative Psychology, 23, 723-733.

Muraco, H., Cheng, A., Arn, D., Ravida, N., Hudson, J., \& Durrant, B. (2009). A new approach to luteinizing hormone detection in the bottlenose dolphin (Tursiops truncatus). Aquatic Mammals, 35, 386-393. 
Nachtigall, P. E., \& Hall, R. W. (1984). Taste reception in the bottlenose dolphin. Acta Zoologica Fennica, 172, $147-148$.

Nachtigall, P. E. (1986). Vision, audition and chemoreception in dolphins and other marine mammals. In R. J. Schusterman, J. A. Thomas, \& F. G. Wood (Eds.), Dolphin cognition and behavior: A comparative approach. (pp. 79-113). Hillsdale, NJ: Lawrence Erlbaum Associates.

Peichl, L., Behrmann, G., \& Kröger, R. H. H. (2001). For whales and seals the ocean is not blue: A visual pigment loss in marine mammals. European Journal of Neuroscience, 13, 1520-1528.

Pfaff, D. W. (1973). Luteinizing hormone-releasing factor potentiates lordosis behavior in hypophysectomized ovariectomized female rats. Science, 182, 1148-1149.

Pineda, M. (2003). Female reproductive system in Pineda, M., \& Dooley, M. (Eds.) McDonald's veterinary endocrinology and reproduction, 5th ed. (pp. 303-306). Ames, IA: Iowa State Press.

Puente, A. E., \& Dewsbury, D. A. (1976). Courtship and copulatory behavior of bottlenosed dolphins. Cetology, 21, $1-9$.

Ridgway, S. H. (1972). Mammals of the sea: Biology and medicine. Springfield, IL: Charles C Thomas.

Robeck, T. R., Steinman, K. J., Yoshioka, M., Jensen, E., O’Brien, J. K., Katsumata, E.,...Monfort, S. L. (2005). Estrous cycle characterization and artificial insemination using frozen-thawed spermatozoa in the bottlenose dolphin Tursiops truncatus. Reproduction, 129, 659-674.

Tilton, J. E., Foxcroft, G. R., Ziecik, A. J., Coombs, S. L., \& Williams, G. L. (1982). Time of the preovulatory LH surge in the gilt and sow relative to the onset of behavioral estrus. Theriogenology, 18, 227-236.

Wells, R. S. (1984). Reproductive behavior and hormonal correlates in Hawaiian spinner dolphins Stenella longirostris. Reports of the International Whaling Commission,. Special Issue, 6, 465-472.

Yablokov, A. V. (1961). The sense of smell in marine mammals. Trudy Soveshchanii Ikhtiol Komissiya Akad Nauk SSSR, 12, 87-93. 